PARCZEWSKI, K., ROMANISZYN, K., WNĘK, H. Influence of electric motors assembly in hubs of vehicle wheels on the dynamics of movement, especially on surfaces with different adhesion coefficient. Combustion Engines. 2019, 179(4), 58-64. DOI: $10.19206 / \mathrm{CE}-2019-409$

\title{
Influence of electric motors assembly in hubs of vehicle wheels on the dynamics of movement, especially on surfaces with different adhesion coefficient
}

The article presents issues related to the drivability and stability of a vehicle equipped with electric motors placed in the hubs of wheels. In the article was presented the necessary modifications to the vehicle and their impact on the vehicle's motion parameters. Describes the behavior of the vehicle on a homogeneous surface and on surfaces with different adhesion coefficient under the wheels of the vehicle sides. The simulation model is presented. The last part of the article presents simulation results for compared surfaces with different adhesion under the wheels of the left and right side of the vehicle.

Key words: vehicle motion dynamics, electric vehicle drive, electric motors in hubs of wheels

\section{Introduction}

The simplicity of construction and control, high efficiency, no exhaust emissions, low noise and lower failure rate of electric vehicles contribute to increasing their quantity.

On the other hand the charging time, the location of the charging station and the weight of the batteries limit the development of electromobility. Intensive development works related with increasing the electric capacity of batteries and shortening their charging time allow to hope that electric vehicles will be widespread in the near future $[7,8]$.

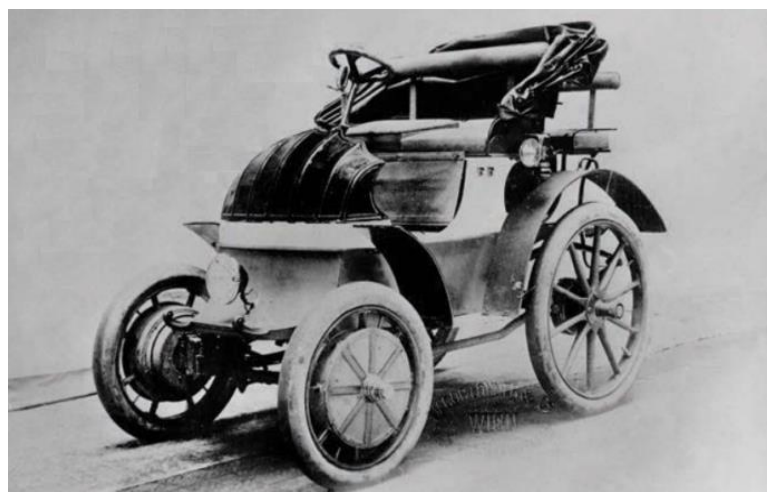

Fig. 1. The in-wheel motors vehicle developed by Lohner and Porsche in $1898[10]$

Electric vehicles with motors built in wheels are increasingly being considered. This placing of the motors increases the inertia of the wheels and the unsprung masses affecting the dynamics of the vehicle motion, the steerability, the safety and the users comfort. The study of the unsprung masses impact on the dynamics of vehicle motion was taken by many authors [2-6]. The requirements for motors which must have a high torque to start and accelerate the vehicle are also increasing. The increasing of unsprung masses will also affect the behavior of the vehicle during braking, especially on surfaces with non-uniform coefficient of adhesion ( $\mu$-split). This issue is discussed later in the article. The article presents the results of braking and acceleration analysis of the vehicle on homogeneous surfaces and with different coefficients of adhesion under the wheels of the right and left side. A method of assessing the behavior of the vehicle while moving on such surfaces is also proposed.

\section{The vehicle modifications resulting from} the installation of electric motors in wheels

In a car with in-wheels motors, there will be no power unit in the engine compartment; however, this place will be used for the installation of the controller, inverter, cooling system and battery. Suspensions and steering system must also be available there. It was assumed that the vehicle body weight will not change. The changes will apply to the wheels in which electric motors will be mounted. This assumption results from the fact that the anticipated electric vehicle will be built on the basis of an existing vehicle powered by an internal combustion engine.

The parameters of the SMzs200S32 electric traction motors built by KOMEL, intended for installation in wheel hubs, were used for the analyses.

These are synchronous motors excited with permanent magnets with liquid cooling (Fig. 2) [1].

The parameters of the SMzs200S32 electric motor are shown in Table 1.
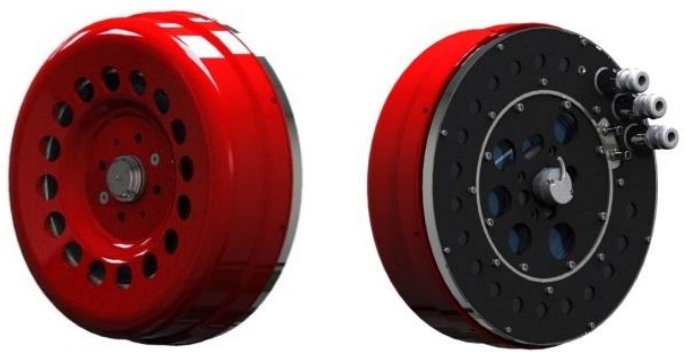

Fig. 2. The 3D model of the SMZs200S32 motor made by KOMEL [1]

Table 1. Parameters of electric motor drive [1]

\begin{tabular}{|l|c|c|}
\hline \multicolumn{1}{|c|}{ Parameter } & Symbol & Value \\
\hline Voltage & $\mathrm{U}_{\mathrm{LL}}[\mathrm{V}]$ & 200 \\
\hline Nominal power & $\mathrm{P}_{\mathrm{n}}[\mathrm{kW}]$ & 42 \\
\hline Nominal torque & $\mathrm{M}_{\mathrm{n}}[\mathrm{Nm}]$ & $400\left(\right.$ for $\left.\mathrm{n}_{\mathrm{n}}=0-\div 10001 / \mathrm{min}\right)$ \\
\hline Max. power & $\mathrm{P}_{\max }[\mathrm{kW}]$ & $\sim 80$ \\
\hline Max torque & $\mathrm{M}_{\max }[\mathrm{Nm}]$ & $\sim 90\left(\right.$ for $\left.\mathrm{n}_{\mathrm{n}}=0-8501 / \mathrm{min}\right)$ \\
\hline
\end{tabular}


Motors with similar parameters are offered by Protean (Fig. 3) [9].

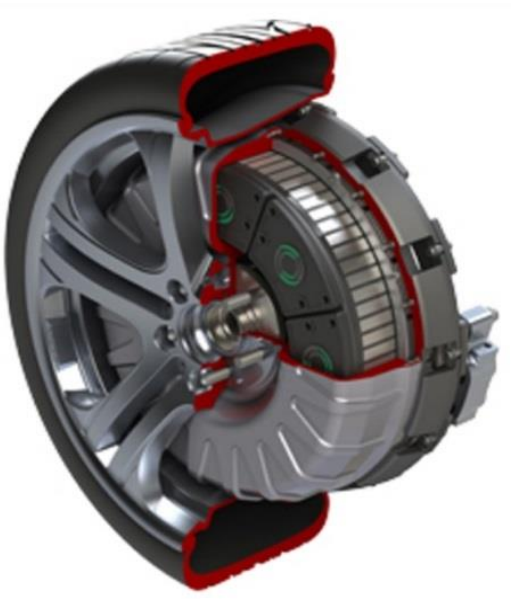

Fig. 3. Electric motor mounted in wheel hub made by Protean [9]

Based on preliminary analyses, it has been established that a $B$ class vehicle $\left(\mathrm{d}_{\mathrm{mc}} \approx 1300 \mathrm{~kg}\right)$, equipped with two motors of this type should provide the required driving dynamics. For cars with a heavier weight, a solution with four drive motors should be used to obtain a suitably high driving performance.

A motor can be divided into fixed elements and movable elements. The motor rotor is an external element consisting of a magnetic core with mounted permanent magnets. The non-rotating motor unit mounted to the suspension consists of an anchor disc, a labyrinth cooling system and a stator consisting of a wound magnetic core. The brake was built inside the wheel.

To analyze vehicle motion dynamics, the parameters of the SMzs200S32 engine were used. An alternative motor location was considered: in the rear wheel hubs, front wheels or in all class B wheels.

\section{The scope of simulation tests}

The aim of the authors was to show the differences in the behavior of vehicles powered by an internal combustion engine and electric engines placed in wheels. It was assumed that the mass of a vehicle equipped with an internal combustion engine will be similar to a vehicle equipped with an electric drive (only the masses of the wheels and their moments of inertia will increase). In the case of comparing vehicles with motors placed on the front or rear axle, all drive torque will be generated by these engines. In the event that both axes are driven, the torque will be separated by 50:50. The comparisons concerned the parameters of vehicle movement during a straight maneuver of acceleration and braking on the roadway of a high coefficient of adhesion and on a surface with different coefficients of adhesion under the wheels of the right and left side of the vehicle.

The following criteria were used to assess the vehicle motion for the straight line track: braking distance to stop the vehicle, deviation from the rectilinear direction of travel and the rate of braking intensity.
Simulation tests were carried out according to the established program.

A range of tests was adopted, in which the vehicle without drive motors placed in wheels was compared with a vehicle equipped with engines. The following cases of power transmission solutions with electric motors placed in the wheels were considered:

- engines placed in the rear wheels of the vehicle,

- engines placed in the front wheels of the vehicle,

- engines placed in all wheels of the vehicle.

The vehicle behaviour was analysed on the surfaces with:

- uniform coefficient of adhesion $(\mu=0.8)$ for attempts to accelerate and stop the vehicle,

- different coefficients of adhesion under the right and left wheels of the vehicle ( $\mu$-split, $\mu_{1}=0.8, \mu_{2}=0.3$ ) for attempts to accelerate and brake the vehicle.

The braking on the straight section of the road has been simulated, taking into account the operation of the ABS system. During the analyses, the own simulation program of the vehicle motion model was used [14].

\section{A simulation model used for vehicle traffic analysis}

In order to conduct a theoretical analysis of the impact of mounting of electric motors in vehicle wheels on the dynamics of motion, a mathematical model of the vehicle was developed.

In the model, the vehicle's basic movement was described using Cartesian coordinate system (position and orientation). The vehicle was treated as a set of rigid solids connected by flexible elements, resilient and damping. Flexible ties were imposed on the suspension movements and the turning movements of the front wheels.

To analyse the dynamics of the car a quasi-spatial model, which has 11 degrees of freedom, has been adopted. It takes into account:

- displacement, velocity and acceleration of the vehicle determined by the coordinates $x_{c}, y_{c}$ (displacement of the vehicle mass center) and angle $\psi$ of the vehicle rotation about $\mathrm{z}_{\mathrm{c}}$ axis,

- angles of wheel rotation $\varphi_{\mathrm{k}}(\mathrm{k}=1,2,3,4)$,

- a steering model that includes: the steering angle of the front wheels $\delta_{1}, \delta_{2}$, the rack movement $\mathrm{x}_{\mathrm{L}}$ and the rotation angle of the steering wheel $\varphi_{\mathrm{w}}$,

- vertical movement of the vehicle $z_{c}$ and rotation angles $\theta, \varphi$ (longitudinal and transversal) without taking into account inertia forces corresponding to the coordinates,

- variability of normal and tangential reactions between the wheels of the car and the surface (model of cooperation of the rubber wheel with the surface by Dugoff, Fancher, Segel $[11,12]$ later modified by Uffelmann [13]),

- anti-lock braking system ABS.

The choice of such a model was determined by the range of interesting parameters of the research object and the scope of research. A model with a similar degree of complexity was used in [12], where the results of computer and research calculations were sufficiently compatible, even though it was also a quasi-spatial model. 
The model adopted some simplifications, which assume, among others, that:

- the road surface is perfectly flat, horizontal and nondeformable,

- the impact of the drive system on the road wheels is taken into account in the form of driving moments,

- the characteristics of elastic elements of suspensions and tyres will be linear,

- pivot axle is perpendicular to the road surface,

- the offset radius will be changed by moving the wheel (changing the track width).

Figure 4 shows the scheme of the analysed system.

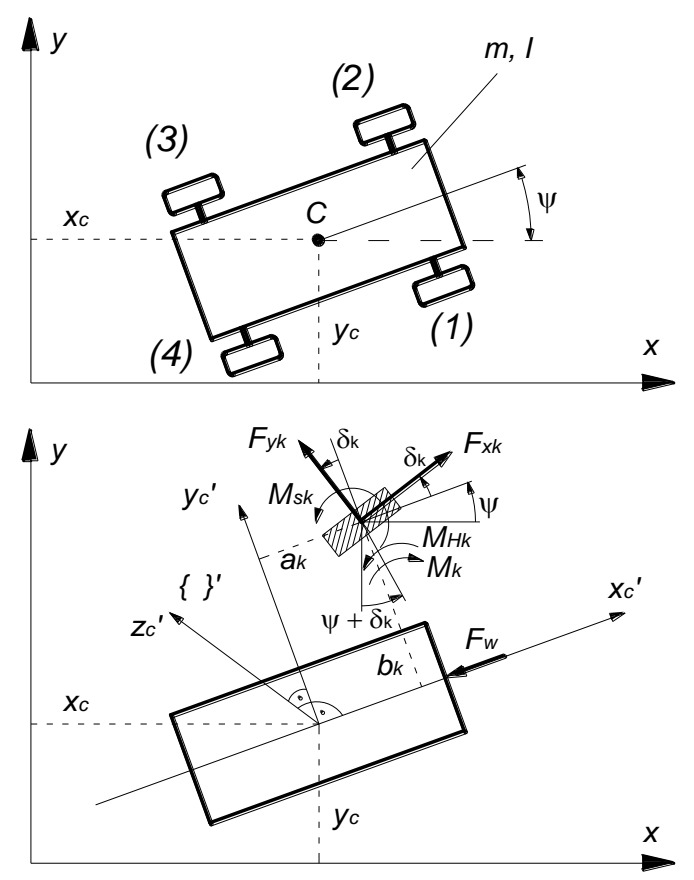

Fig. 4. Forces and moments acting on the vehicle [14]

$$
\begin{aligned}
& \mathrm{m} \ddot{x}_{\mathrm{c}}=\sum_{\mathrm{k}=1}^{4} \mathrm{~F}_{\mathrm{xk}} \cos \left(\psi+\delta_{\mathrm{k}}\right)-\sum_{\mathrm{k}=1}^{4} \mathrm{~F}_{\mathrm{yk}} \sin \left(\psi+\delta_{\mathrm{k}}\right)-\mathrm{F}_{\mathrm{w}} \cos \psi \\
& \mathrm{m} \ddot{y}_{\mathrm{c}}=\sum_{\mathrm{k}=1}^{4} \mathrm{~F}_{\mathrm{xk}} \sin \left(\psi+\delta_{\mathrm{k}}\right)+\sum_{\mathrm{k}=1}^{4} \mathrm{~F}_{\mathrm{yk}} \cos \left(\psi+\delta_{\mathrm{k}}\right)-\mathrm{F}_{\mathrm{w}} \sin \psi \\
& \mathrm{I} \ddot{\Psi}_{\mathrm{c}}=\sum_{\mathrm{k}=1}^{4}\left\{-\mathrm{b}_{\mathrm{k}}\left[\mathrm{F}_{\mathrm{xk}} \cos \delta_{\mathrm{k}}-\mathrm{F}_{\mathrm{yk}} \sin \delta_{\mathrm{k}}\right]+\mathrm{a}_{\mathrm{k}}\left[\mathrm{F}_{\mathrm{xk}} \sin \delta_{\mathrm{k}}+\mathrm{F}_{\mathrm{yk}} \cos \delta_{\mathrm{k}}\right]+\sum_{\mathrm{k}=1}^{4} \mathrm{M}_{\mathrm{sk}}\right\} \\
& \mathrm{I}_{\mathrm{k}} \ddot{\varphi}_{\mathrm{k}}=\mathrm{M}_{\mathrm{k}}-\mathrm{M}_{\mathrm{Hk}}-\mathrm{F}_{\mathrm{xk}} \cdot \mathrm{r}_{\mathrm{dk}}+\mathrm{F}_{\mathrm{zk}} \cdot \mathrm{f}_{\mathrm{k}}^{\prime} \quad(\mathrm{k}=1,2,3,4)
\end{aligned}
$$

where: $F_{x k}, F_{y k}, F_{z k}-$ component forces of the interaction between road surface and the wheel $(\mathrm{k}=1,2,3,4), \mathrm{M}_{\mathrm{sk}}-$ aligning moment, $\mathrm{F}_{\mathrm{w}}$ - air drag, $\mathrm{m}$ - vehicle mass, $\mathrm{I}-$ the mass moment of vehicle inertia about the z-axis, $\psi$ - yaw angle, $\delta_{\mathrm{k}}$ - steering angle of the wheel (for rear wheels $\delta_{3}=$ $\delta_{4}=0$ is assumed), $I_{k}$ - the mass moment of inertia of the wheel about its axis of rotation, $\varphi_{\mathrm{k}}-$ wheel rotation angle $(\mathrm{k}$ $=1,2,3,4), \mathrm{M}_{\mathrm{k}}-$ drive moment, $\mathrm{r}_{\mathrm{dk}}-$ dynamic radius of the wheel, $\mathrm{f}_{\mathrm{k}}^{\prime}$ - substitutive coefficient:

$$
f_{k}^{\prime}=\frac{F_{x k}-f_{k} \cdot F_{z k}}{C_{o p}}
$$

$\mathrm{M}_{\mathrm{Hk}}$ - braking moment, $\mathrm{f}_{\mathrm{k}}$ - rolling drag coefficient, $\mathrm{C}_{\mathrm{op}}-$ tyre peripheral stiffness index (the same for all wheels).

In addition, it was assumed that for $\mathrm{k}=1,2,3,4$ forces acting on wheels in the plane of the roadway, and aligning moments, are expressed by the following formulas:

$$
\begin{gathered}
\mathrm{F}_{\mathrm{xk}}=\alpha_{\mathrm{k}} \cdot \mathrm{N}_{\mathrm{k}} \\
\mathrm{F}_{\mathrm{yk}}=\beta_{\mathrm{k}} \cdot \mathrm{N}_{\mathrm{k}} \\
\mathrm{M}_{\mathrm{sk}}=\gamma_{\mathrm{xk}} \cdot \mathrm{F}_{\mathrm{xk}}+\gamma_{\mathrm{yk}} \cdot \mathrm{F}_{\mathrm{yk}}+\gamma_{\mathrm{ko}}\left(\mathrm{F}_{\mathrm{xk}} \mathrm{F}_{\mathrm{yk}}\right)=\gamma_{\mathrm{ko}}+\gamma_{\mathrm{k}} \cdot \mathrm{N}_{\mathrm{k}}
\end{gathered}
$$

where: $\gamma_{\mathrm{k}}=\alpha_{\mathrm{k}} \cdot \gamma_{\mathrm{xk}}+\beta_{\mathrm{k}} \cdot \gamma_{\mathrm{yk}}, \gamma_{\mathrm{ko}}=\gamma_{\mathrm{ko}}\left(\mathrm{F}_{\mathrm{xk}} \mathrm{F}_{\mathrm{yk}}\right)$, has a value calculated in the previous step during the integration of the equations of motion, $\mathrm{N}_{\mathrm{k}}=\mathrm{F}_{\mathrm{zk}}$ - normal forces acting on the wheel $\mathrm{k}=1,2,3,4, \alpha_{\mathrm{k}}, \beta_{\mathrm{k}}, \gamma_{\mathrm{xk}}, \gamma_{\mathrm{yk}}, \gamma_{\mathrm{ko}}$ - coefficients calculated for the adopted model of cooperation of the wheel tyre with the road surface according to Dugoff [11].

Based on the adopted vehicle model, a computer program was developed. It allows you to define any road surface configurations under the wheels of the tested vehicle. It also allows you to simulate the operation of the ABS system. For this purpose, an appropriate algorithm that allows the implementation of the functions of this system, has been developed. There is also the possibility of requesting the desired drive and braking torque for individual wheels, as well as the actual driving and braking torque during road tests.

\section{Simulation tests}

\subsection{Speeding the vehicle straight ahead on a road with homogeneous high adhesion coefficient}

During the simulation test in speeding the vehicle, the steering wheel was maintained with a zero steering angle. The same driving torque was assumed for a vehicle equipped with an internal combustion engine and a vehicle with electric motors in wheel hubs, with the difference that in the case of vehicles with four-wheel drive, the torque was divided 50:50 for axles: front and rear.

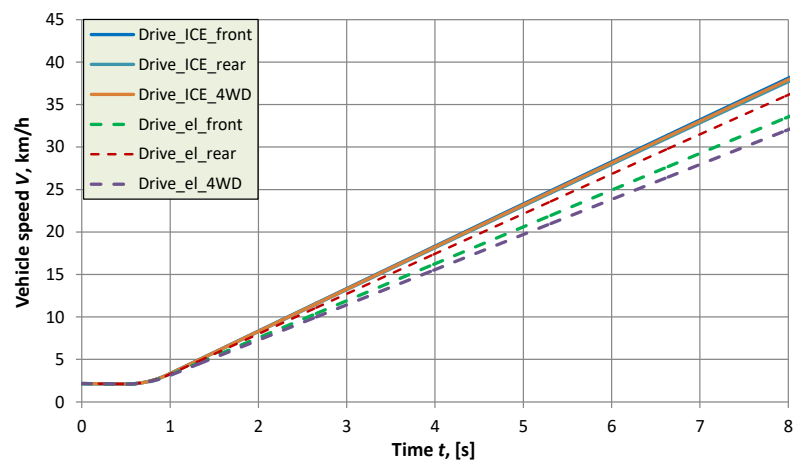

Fig. 5. Vehicle speed in speeding the vehicle straight ahead on a road with homogeneous high adhesion coefficient (ICE - internal combustion engine, el - electric motor) [own research]

Figure 5 shows the speed of a vehicle equipped with various propulsion systems configurations. The graphs show that the vehicle with classic drive achieves higher end speeds (after 8 second). The vehicle with electric motors in the wheel hubs, due to the higher weights, achieves lower end speeds, especially for the $4 \times 4$ drive system. A car with elec- 
tric motors in the rear wheel hubs accelerates to a higher speed than with the electric motors in the front wheel hubs.

To assess the acceleration of the vehicle, the coefficient of acceleration intensity by analogy to the braking ratio coefficient of the vehicle was used, which is the ratio of vehicle acceleration to gravity acceleration.

Figure 6 presents the average values of the acceleration intensity coefficient of the vehicle equipped with various configurations of propulsion systems. The graphs show that a vehicle powered by an internal combustion engine achieves similar acceleration intensities $(\sim 0.14)$ regardless of whether it is an front or rear drive system, or all wheels drive system. In the case of vehicles with electric motors in the wheel hubs, the vehicle with electric motors mounted on the rear axle gets the highest acceleration intensity, the smaller ones are obtained in the case of electric motors on the front axle and electric motors driving all the wheels.

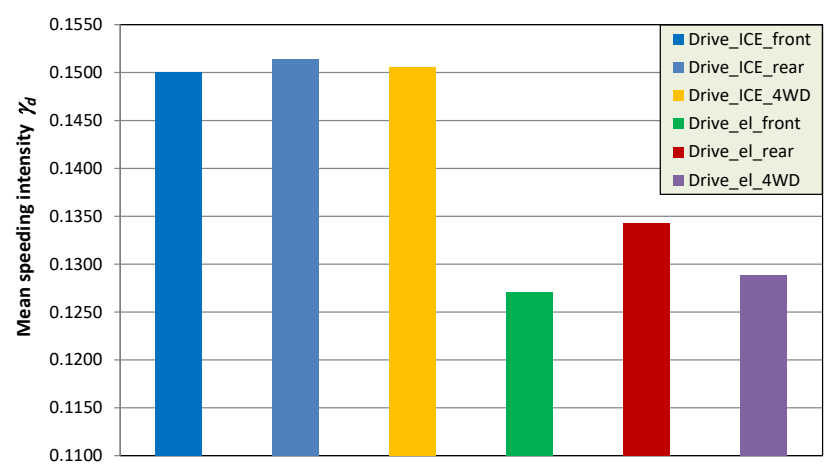

Fig. 6. Mean speeding intensity in speeding the vehicle straight ahead on a road with homogeneous high adhesion coefficient [own research]

\subsection{Acceleration of the vehicle while driving straight ahead on the road surface with different coefficients of adhesion under the wheels of the right and left side of the vehicle}

Similarly to the simulation tests, speeding at the road with uniform coefficient of adhesion, on the road with different coefficients of adhesion on the left and right side of vehicle, the steering wheel was maintained with a zero steering angle. Similarly, the same driving torque was assumed for a vehicle powered by an internal combustion engine and electric motors, with the difference that in the case of vehicles with all-wheel drive, the drive torque was divided in proportion 50:50 on each axle.

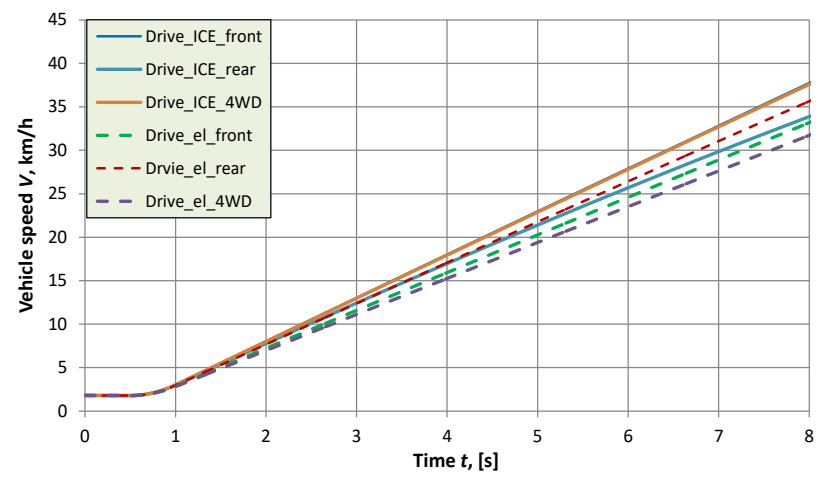

Fig. 7. Vehicle speed in speeding the vehicle straight ahead on a road with different adhesion coefficient under the wheels of the left and right side [own research]
Figure 7 shows the speed of a vehicle equipped with various configurations of propulsion systems, comparing its motion on the road with different coefficients of adhesion under the wheels of the right and left side of the vehicle. The graphs show that the vehicle driven by the internal combustion engine achieves slightly higher final speeds (after 8 second), with the vehicle with the rear drive showing a fairly large deviation from the rectilinear direction of travel. The vehicle powered by electric motors in the rear wheel hubs is characterized by a similar, though slightly lower, speed after 8 seconds of acceleration. Vehicles with engines in wheel hubs, due to the higher moments of inertia of the drive wheels, obtain lower final speeds, especially with the $4 \times 4$ drive system. A car with electric motors in the rear wheel hubs accelerates to a higher speed than with electric motors in the front wheel hubs.

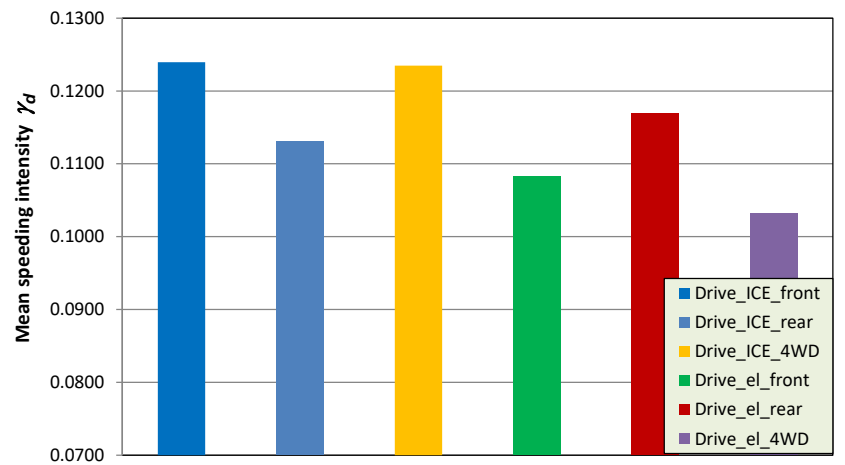

Fig. 8. Mean speeding intensity in speeding the vehicle straight ahead on a road with different adhesion coefficient under the wheels of the left and right side [own research]

Figure 8 presents the average values of the acceleration intensity of the vehicle equipped with various configurations of propulsion systems. The charts show that the vehicle powered by the internal combustion engine achieves similar acceleration intensities $(\sim 0.12)$ for the front drive system and the all-wheel drive. Lower values are obtained with a rear-wheel drive vehicle.

In the case of vehicles with electric motors in the wheel hubs, the vehicle with engines on the rear axle is characterized by the highest acceleration intensity, the smaller ones are obtained in the case of electric motors mounted on the front axle and electric motors driving all wheels.

\subsection{Braking the vehicle while driving straight ahead on a road surface with a high homogeneous coefficient of adhesion}

During braking simulation tests, the steering wheel was maintained with a zero steering angle. The same braking torque was assumed for a vehicle equipped with an internal combustion engine and a vehicle with electric motors in the wheel hubs, with the difference that in the case of vehicles with all-wheel drive, the braking torque was divided in proportion 50:50 for any axle. The anti-lock braking system (ABS) was used during braking.

Figure 9 shows the changes in vehicle speed as a function of the distance traveled to its stop. The vehicle was equipped with various configurations of drive systems. The graphs show that the road to stop the vehicle powered by 
the internal combustion engine is slightly shorter than that for a vehicle equipped with electric motors in the rear axle wheel hubs. This one is shorter than the road to stop in the vehicle with electric drive motors on the front axle. A vehicle with electric engines mounted in all wheels was characterized that it has the longest way to stop. The moments of inertia of the wheels affect the length of the braking distance when the ABS system was used.

Figure 10 presents the average values of the braking ratio of a vehicle equipped with various configurations of propulsion systems. The graph shows that the vehicle powered by the internal combustion engine is characterized by the highest braking ratio $(\sim 0.670)$ for the system with the front drive and electric motors in the wheel hubs ( 0.664), for the rear drive system and electric motors in the wheel hubs $(\sim 0.665)$ and with electric motors in the hubs of all wheels $(\sim 0.652)$.

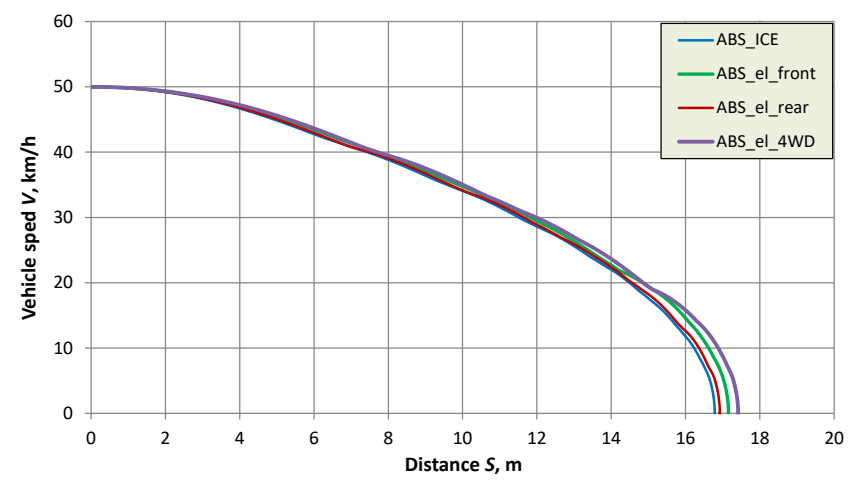

Fig. 9. Distance of stopping the vehicle in braking the vehicle straight ahead on a road with homogeneous high adhesion coefficient [own research]

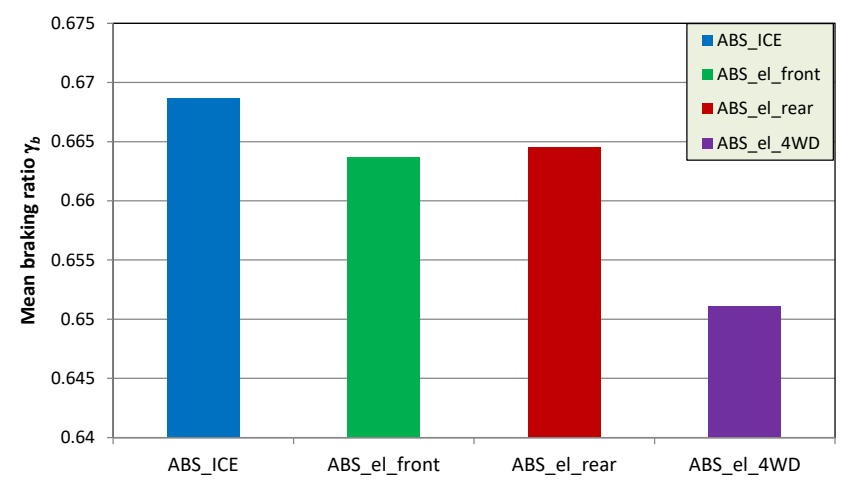

Fig. 10. Mean braking ratio in braking the vehicle straight ahead on a road with homogeneous high adhesion coefficient [own research]

5.4. Braking of the vehicle while driving straight ahead on the road surface with different coefficients of adhesion under the wheels of the right and left side of the vehicle

Similarly to the other simulation tests, the steering wheel was maintained with a zero steering angle. In these tests, the anti-lock braking system (ABS) was also simulated.

Figure 11 shows changes in vehicle speed as a function of the distance traveled to its stop. The graph shows that the road to stop the vehicle with the combustion engine used to drive and for the vehicle equipped with electric motors to drive mounted on the front axle is almost the same. The vehicles with electric motors in the rear wheel hubs and in the hubs of all wheels were characterized by a little more stopping distance.

Figure 12 presents the average values of the braking ratio of a vehicle equipped with various configurations of propulsion systems. The graphs show that the vehicle powered by electric motors in the front wheel hubs has the highest braking ratio $(\sim 0.397)$ for a vehicle powered by an internal combustion engine $(\sim 0.387)$, for a vehicle powered by electric motors placed in the rear wheel hubs and with electric motors in the hubs of all wheels is $(\sim 0.337)$.

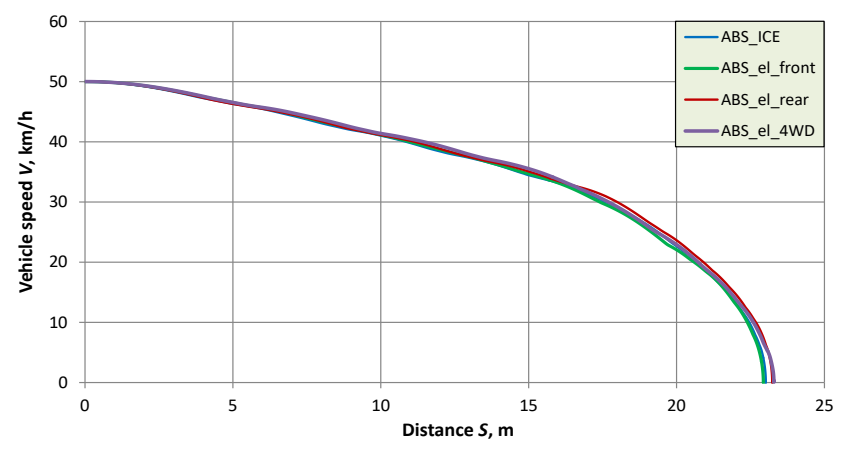

Fig. 11. Distance of stopping the vehicle in braking the vehicle straight ahead on a road with different adhesion coefficient under the wheels of the left and right side [own research]

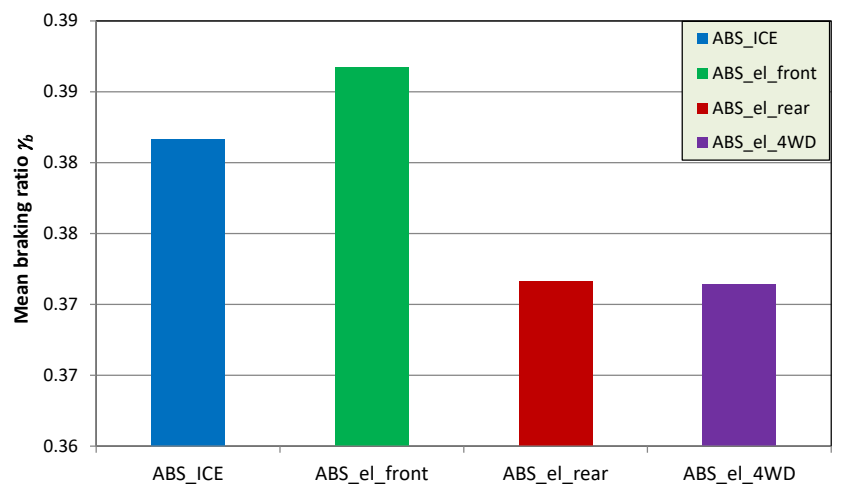

Fig. 12. Mean braking ratio in braking the vehicle straight ahead on a road with different adhesion coefficient under the wheels of the left and right side [own research]

\section{Analysis of the behavior of the vehicle on the road with the same and different coefficient of adhesion under the wheels of the right and left side of the vehicle}

Comparing of accelerating of the vehicle on a straight path of road with a high coefficient of adhesion $(\mu=0.8)$ with acceleration on the road with different coefficients of adhesion under the right wheels $(\mu=0.3)$ and the left side of the vehicle $(\mu=0.8)$ it was noticed that in the first case the distance traveled in the first 8 seconds was in the range from 37 to $43 \mathrm{~m}$ and in the second case from 32 to $37 \mathrm{~m}$. Larger moment of inertia of the wheels with electric motors mounted in hubs affect the speed after 8 second of vehicle movement. The mean acceleration intensity of the vehicle driven by combustion engine, without the increased weight of the wheels and without the larger moments of inertia is almost constant and amounts to $\sim 0.14$ After the installation 
of electric motors in the wheels, mean acceleration intensity is lower, from $\sim 0.12$ to $\sim 0.135$.

The acceleration on the road with different coefficients of adhesion results in a reduction of the mean acceleration intensity from $\sim 0.105$ to $\sim 0.112$. The smallest acceleration intensity is characterized by the solution of the drive system with the motors located in the hubs of all wheels.

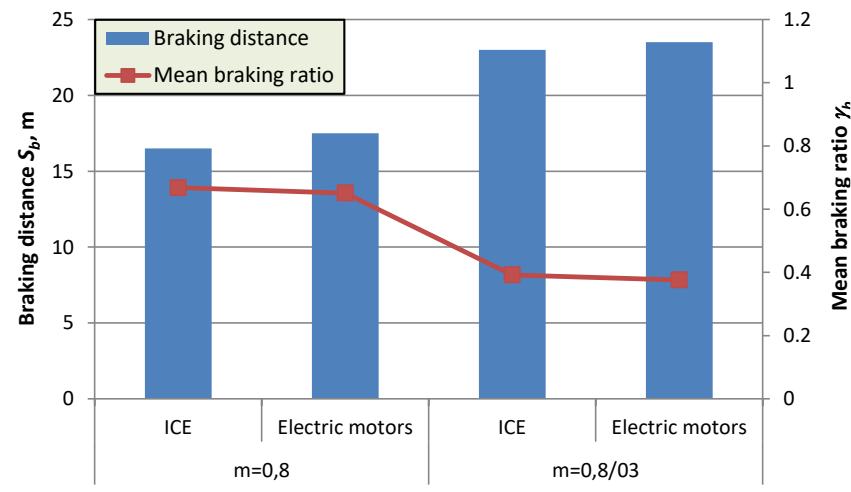

Fig. 13. Comparison of braking in an attempt to drive straight ahead on a road with high homogeneous and different adhesion coefficient under the wheels of the left and right side [own research]

The braking distance to stop of the vehicle on a straight path of road with a high coefficient of adhesion is from $16.5 \mathrm{~m}$ to $17.5 \mathrm{~m}$. In the case of braking on the road with different coefficients of adhesion, it is extended to $23-23.5$ $\mathrm{m}$. The braking ratio in first case is from $\sim 0.668$ to $\sim 0.651$. Braking on the road with different coefficients of adhesion reduces the braking ratio to $0.392-0.367$.

The vehicle with electric motors placed in the hubs of all wheels is characterized by the lowest braking intensity indices. It is caused by the increase of vehicle mass and wheels mass as well as moments of inertia of the wheels, which change their rotational speed during the operation of the ABS system.

Figure 13 presents a comparison of vehicle braking with and without electric motors in wheel hubs on road surfaces with a high coefficient of adhesion and different coefficients of adhesion under the right and left wheels of the vehicle. Mounting electric drive motors in the vehicle's wheel hubs has little effect on increasing the braking distance and changing the braking ratio. A much greater im- pact is observed in braking on the case of road with different coefficients of adhesion ( $\mu$-split).

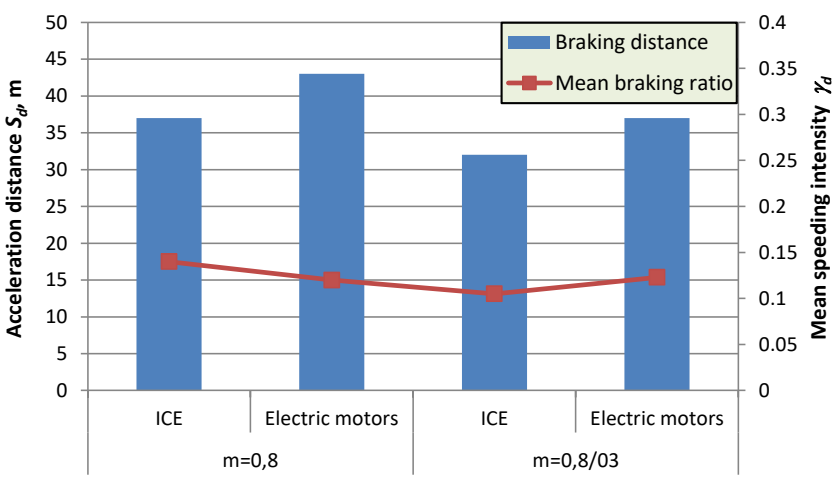

Fig. 14. Comparison speeding the vehicle in an attempt to drive straight ahead on a road with high homogeneous and different adhesion coefficient under the wheels of the left and right side [own research]

Figure 14 presents a comparison of acceleration of vehicles equipped without and with electric motors in wheel hubs on the road surfaces with a high coefficient of adhesion and different coefficients of adhesion under the wheels of the right and left side of the vehicle. Mounting drive motors in the wheel hubs of the vehicle contributes to the extension of the acceleration path and the reduction of its intensity. The influence of different coefficients of adhesion ( $\mu$-split) on the length of the acceleration path and its intensity is less than in the case of braking the vehicle.

\section{Summary and conclusions}

The paper presents preliminary simulation tests of a vehicle powered by electric motors placed in wheel hubs. For comparison, a vehicle with an internal combustion engine (smaller wheel masses and their moments of inertia) was also analyzed. The analysis was based on calculations using the original program described in the literature [14].

The use of electric motors placed in the wheel hubs for driving the vehicle reduces the driving comfort, but also changes the moment of inertia of the wheels. Especially during acceleration and intensive braking, the increase of masses and moments of inertia of the wheels will result in lowering both the intensity of the acceleration and the braking intensity of the vehicle.

\section{Nomenclature}

ABS anti-lock braking system

$\mu$-split different coefficients of adhesion under the right side $(\mu=0.3)$ and the left side of the vehicle $(\mu=0.8)$

\section{Bibliography}

[1] DUKALSKI, P., BĘDKOWSKI, B., PARCZEWSKI, K. et al. Dynamics of the vehicle rear suspension system with electric motors mounted in wheels. Eksploatacja $i$ Niezawodnosc - Maintenance and Reliability. 2019, 21(1), 125-136.

[2] LALITKUMAR, MAIKULAL JUGULKAR, SHANKAR, SINGH, SURESH, MARUTI SAWANT. Analysis of suspension with stiffness and variable damping force for auto- motive applications. Advances in Mechanical Engineering. 2016, 8(5), 1-19.

[3] ANDERSON, M., HARTY, D. Unsprung mass with inwheel motors - myths and realities. 10th International Symposium on Advanced Vehicle Control. Loughborough 2010.

[4] ABDUSSALAM ALI AHMED OMAR, BAŞAR ÖZKAN. Analysis of effect of in-wheel electric motors mass on passive and active suspension systems. ARPN Journal of Engineering and Applied Sciences. 2015, 10(14). 
[5] RAJAMANI, R. Vehicle Dynamics and Control. Springer publications. second edition 2012.

[6] ŚLASKI, G., GUDRA, A., BOROWICZ, A. Analysis of the influence of additional unsprung mass of in-wheel motors on the comfort and safety of a passenger car. Archives of Automotive Engineering. 2014, 65(3), 51-64.

[7] DZIDA, J. Porównanie różnych sposobów kierunkowego napędzania pojazdów silnikami elektrycznymi. Napędy $i$ XSterowanie. 2017, 2, 50-55.

[8] MERKISZ, J., PIELECHA, I. Układy elektryczne pojazdów hybrydowych. Wydawnictwo Politechniki Poznańskiej. Poznań 2015.

[9] https://www.electricvehiclesresearch.com/articles/4577/ protean-electric-to-produce-in-wheel-electric-drive-systemsin-china

[10] Lohner-Porsche Mixte Voiturette, http://www.ultimatecarpage.com/pic/3456/Lohner-Porsche-MixteVoiturette_2. html, November 2007, accessed 25th July 2010

Krzysztof Parczewski, DSc., DEng. - Faculty of Mechanical Engineering and Computer Science, University of Bielsko-Biała.

e-mail: kparczewski@ath.bielsko.pl

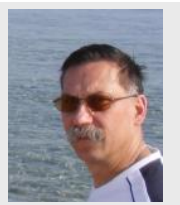

Henryk Wnęk, DEng. - Faculty of Mechanical Engineering and Computer Science, University of Bielsko-Biała.

e-mail: hwnek@ath.bielsko.pl
[11] DUGOFF, H., FANCHER, P.S., SEGEL, L. Tire performance characteristics affecting vehicle response to steering and braking control inputs. Highway Safety Research Institute. University of Michigan. Ann Arbor. Final Report National Bureau of Standards Contract CST-460, 1969.

[12] GRZEGOŻEK, W. Modelowanie dynamiki samochodu przy stabilizującym sterowaniu siłami hamowania. Zeszyty Naukowe Politechniki Krakowskiej. Seria Mechanika. Monografia 275. Kraków 2000.

[13] UFFELMANN F.: Berechnung des Lenk und Bremsverhaltens von Kraftfahrzeugzugen auf rutschiger Fahrbahn. Eingereichte Dissertation. TU Braunschweig 1979.

[14] WNĘK, H. Analiza wpływu promienia zataczania na przebieg procesu hamownia pojazdu z systemem ABS. Wydawnictwo ATH. Bielsko-Biała 2005.

Kazimierz Romaniszyn, DSc., DEng. - Faculty of Mechanical Engineering and Computer Science, University of Bielsko-Biała.

e-mail: kromaniszyn@ath.bielsko.pl
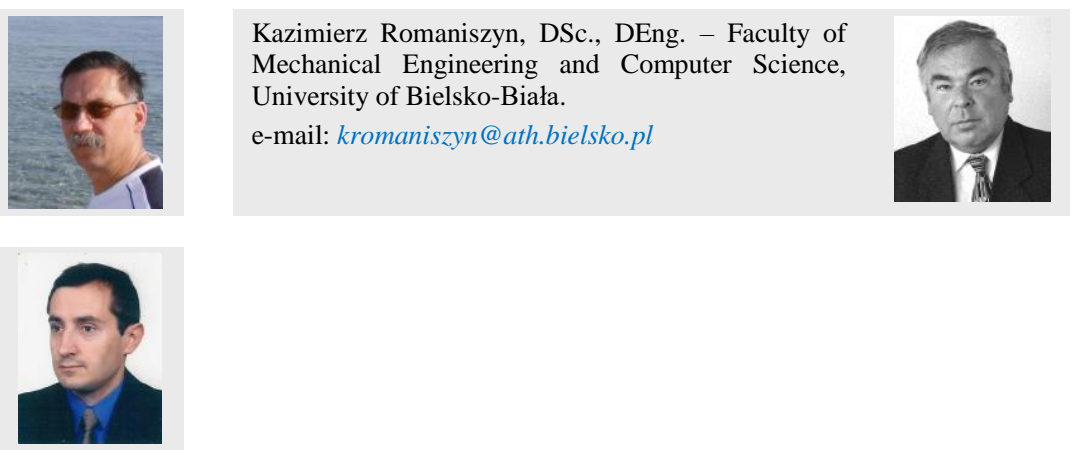